\title{
Effect of Shot Peening on Mechanical Properties for Steel AISI 1008
}

\author{
Mohammed Abdulraoof Abdulrazzaq, Zeyad D. Kadhim, Wassan S. Hussain \\ Department of Mechanical Engineering, College of Engineering, AL-Mustansiriyah University \\ mohammedraof415@yahoo.com
}

\begin{abstract}
Residual stress has a significant effect for improving engineering properties for metals .Most of the surface treatments produce compressive residual stress at the metal surfaces, which reduce crack initiation and increasing the metal resistance to fatigue, which is shot peening process. Shot peening is usually used for this purpose for producing plastic deformations of surface of the metal which can lead to creation high residual compressive stresses at metal surface. This research include study the influence of shot peening process on fatigue resistance, surface hardness and surface roughness for low carbon steel (AISI 1008). This process accomplished with different times which were $(10,20$ and 30)minutes. The result of the fatigue test showed that the fatigue limit increase when shot peening time increased and the best fatigue limit obtained when shot peening process was carried out at 30 minutes. Results of hardness test showed that surface hardness increased with increase of shot peening time. It can be seen that highest value of surface hardness is obtained from shot peening process at time (30 minutes) which is (235.1 HVN). Results of surface roughness test showed that the surface roughness of metal increased when time of shot peening increased.
\end{abstract}

Keywords: Shot peening; Fatigue properties: Low carbon steel: Surface hardness: Roughness.

\section{Paper History:}

(Received: 5/11/2017, Accepted: 11/2/2018)

\section{Introduction}

Shot peening is a cold working in which surfaces of partsare bombarded with a small spherical media called shot. Each piece of the shot striking material acts as tiny peening hammer and imparting for surface of the part a small indentations or a dimple [1]. This process includes a wide range of process parameters which may have a significant effect on a level of residual stresses and the hardness [2].This process generally increases fatigue life. Plastic deformations induce the residual compressive stresses in peened surfaces, along with tensile stresses in an interior. Tensile stress deep in the part is not as problematic as the tensile stresses on surface because crack is less likely for starting in an interior [3, 4].Generally shot peening raises density of the dislocations in material surfaces layer and because of in homogeneous plastic deformations, residual macro stress is developed and further surfaces topography are changed.
It is usually believed that compressive residual stress in surface layers is a main reason to improve fatigue life due for shot peening processes [5].M.A.S. Torres and H.J.C. Voorwald, 2002 [6] showed that gain of fatigue life of AISI 4340 steel is evaluated under four the shot peening condition. The rotating bending fatigue test was conducted and compressive residual stresses field (CRSF) was measured by an X-ray tensometry during and prior fatigue testing. It was noted that the relaxations of CRSF happened due for fatigue process. Fractured fatigue specimens were achieved by using the scanning electron microscope for obtains the formations about cracks initiation point. S. Van Wijk1 et al., 2010 [7] investigated that shot peening is the effective production process for ensuring the required residual stresses levels. The analysis of orthogonal design of experiments presented for establishing an empirical relationship between the main parameters for the shot peening and residual stresses profiles for the steel. Relationship between maximum residual compressive stresses and shot velocity is developed. The analysis of experimental data investigated that it is possible for optimizing shot peening by a complete controlling of the process parameters. S.M.H. Gangaraj and G.H. Farrahi, 2011 [8] studied effect of shot velocity and size on surface morphology after shot peening process. Results were increase in the shot peening intensity led for increasing in maximum residual compressive stresses and width of CRSF. Hornbogen et al.(1981)[9], point out that shot peening has improved the fatigue life due to surface cold-working than the un peened or bulk-formed (steel) specimen. From results, the cold work increases the material hardness in most materials. Thus, it is clear that cold work and the compressive residual stresses enhance the fatigue life. Herzog et al. (1996)[10] have conducted a set of experiments on $\mathrm{X} 35 \mathrm{CrMo} 17$ steel alloy exploring the influence of different peening parameters. From results, the shot velocity (function of air pressure or wheel speed), diameter, hardness and the peening time (coverage) increase magnitude of maximum compressive residual stress value as well as push its location further inside away from the surface. In addition, shot hardness increases the surface compressive residual stresses value as well. Wang S et al. [11] investigated that shot peening pushes cracks initiation points beneath residual compressive stresses zones in all cases studied except for $0.45 \%$ carbon steel. It is usually that relaxation of the CRSF during fatigue process was not considered.W. Shengping, et.al, [12] (1998) studied fatigue limits for shot peened $20 \mathrm{Cr}, 30 \mathrm{CrMo}, 40 \mathrm{Cr}, \mathrm{GC} 4,45$ steel and $\mathrm{Al}-$ alloy 7075 . Proposed model for predicting apparent 
fatigue limits of shot-peened metal. Three-point the bending fatigue testing was achieved in the highfrequency fatigue-test machine and apparent fatigue limits were determined by up-and-down methods. Local stress at cracks initiation sites have been calculated and result showing that local stress at cracks initiation sites is nearly equal for properly shot-peened metal. M. Guagliano, et.al, [13] (2004) dealt with problems of the predicting and the optimizing fatigue strength for shot peened specimen and studied effect of peening parameters that characterize residual stresses. It was predicted that improving of the fatigue strength due for shot peening process. A series of notched cylindrical specimen peened by using different parameters aimed for determining the improving of fatigue limits of the treated specimen. Results shown that, depth at which the maximum compressive residual stresses happens with respect of material grain size is most important factor in determining fatigue threshold.

\subsection{Material}

The studied material in this work was low carbon steel AISI 1008 that is used in many steel components, such as gears, shafts, cams. Reason for selecting this metal is due to its various applications in industrial field, easy to fabricate, high ductility, available commercially in the form of round bars and its have low cost.

\subsection{Chemical Analysis}

Chemical analysis of the tested material (AISI 1008 low carbon steel) as shown in table (1) was performed by (Thermo ARL 3460, optical Emission spectrometer) in State Company for Inspection and Engineering Rehabilitation (SIER) in Baghdad. Results are compared with American Standard carbon steels Test Method. This chemical analysis carried out at $\left(27.2^{\circ} \mathrm{C}\right)$ and moisture rate $(20 \%)$.

\section{Experimental Work}

Table (1) Chemical Composition of low carbon steel AISI 1008 in wt \%

\begin{tabular}{|c|c|c|c|c|c|c|c|c|c|c|c|}
\hline \multirow{2}{*}{$\begin{array}{c}\text { Material } \\
\text { AISI } \\
1008\end{array}$} & \multicolumn{11}{|c|}{ Chemical Composition } \\
\hline & $\mathrm{C}$ & $\mathrm{Si}$ & $\mathrm{Mn}$ & $\mathrm{P}$ & $S$ & $\mathrm{Cr}$ & Mo & $\mathrm{Ni}$ & $\mathrm{Al}$ & $\mathrm{Cu}$ & $\mathbf{F e}$ \\
\hline $\begin{array}{c}\text { Standard } \\
\text { value }\end{array}$ & $\begin{array}{c}0.10 \\
(\operatorname{Max})\end{array}$ & & $\begin{array}{l}0.3- \\
0.5\end{array}$ & $\begin{array}{l}0.040 \\
(\operatorname{Max})\end{array}$ & 0.05 & & & & & & \\
\hline $\begin{array}{l}\text { Actual } \\
\text { value }\end{array}$ & 0.073 & 0.150 & 0.487 & 0.005 & 0.016 & 0.056 & 0.002 & 0.085 & 0.016 & 0.222 & Bal. \\
\hline
\end{tabular}

\subsection{Stress Relieve for Specimens}

This treatment was carried out by placing the samples in crucible and then put it in the oven at temperature 220
${ }^{\circ} \mathrm{C}$ for three hours to relieve stresses. This treatment carried out in materials engineering department /college of engineering /Al-Mustansiriayah University. Figure (1) shows the electric furnace.

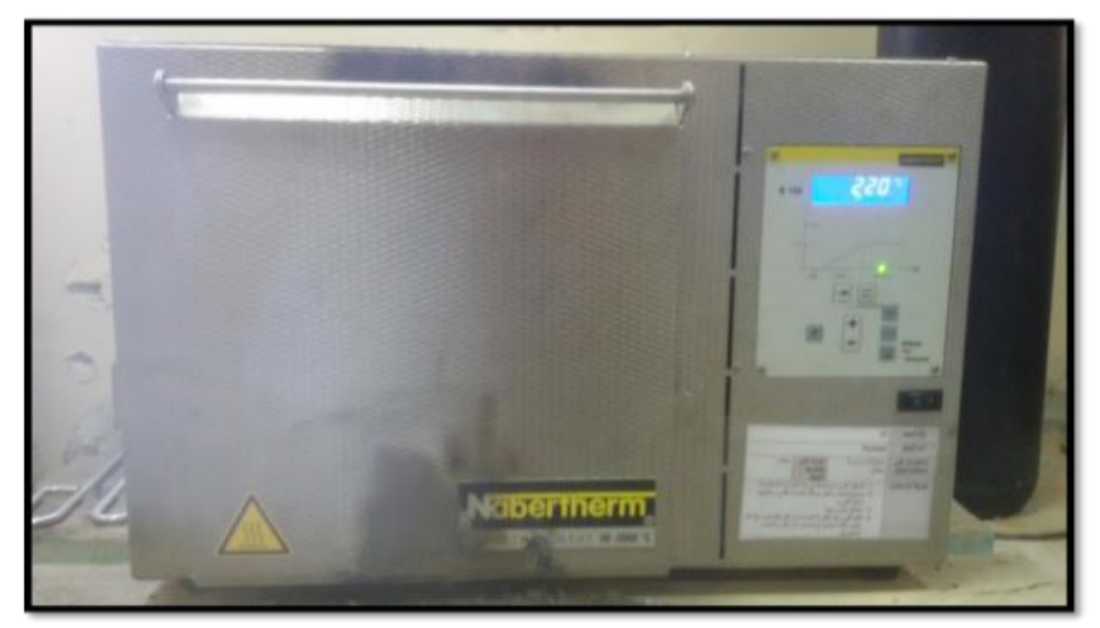

Figure 1 the electric furnace used for heat treatment

\subsection{Shot Peening Process}

The samples are treated with shot peening process from all sides using an air-blast machine. This process 
carried out on thirty samples of fatigue specimens, every group consist of ten samples. First group of samples subjected to ten minutes time of shot peening, second group of samples subjected to twenty minutes time of shot peening and third group subjected to thirty minutes time of shot peening. A ball shot of steel with the hardness of $55 \mathrm{HRC}$ and the nominal diameter of $1 \mathrm{~mm}$ was chosen. For avoiding medium collision, angle of nozzle inclination was shifted by $10^{\circ}$ with a regard to vertical axis. The standoff distance is $100: 1 \mathrm{~mm}$ was maintained, 5 bar average blasting pressure, ball speed is $20 \mathrm{~m} / \mathrm{s}$ and $100 \%$ coverage .Were employed shot peening device used was shot tumblast control (model STB-OB) machine No.03008 05 type. Figure (2) illustrates shot peening device from outside and figure (3) shot peening device from inside with the samples and shot balls. Position of shot peening device was in Institute of technology / workshop plumbing.

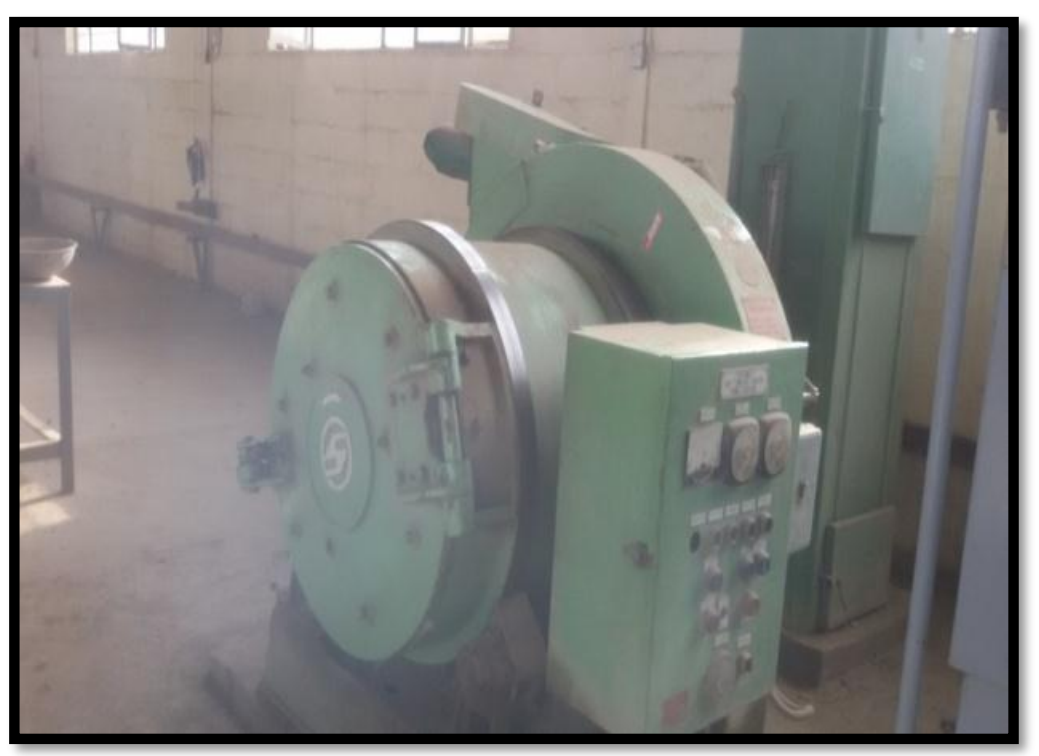

Figure (2) Shot Peening Device from outside

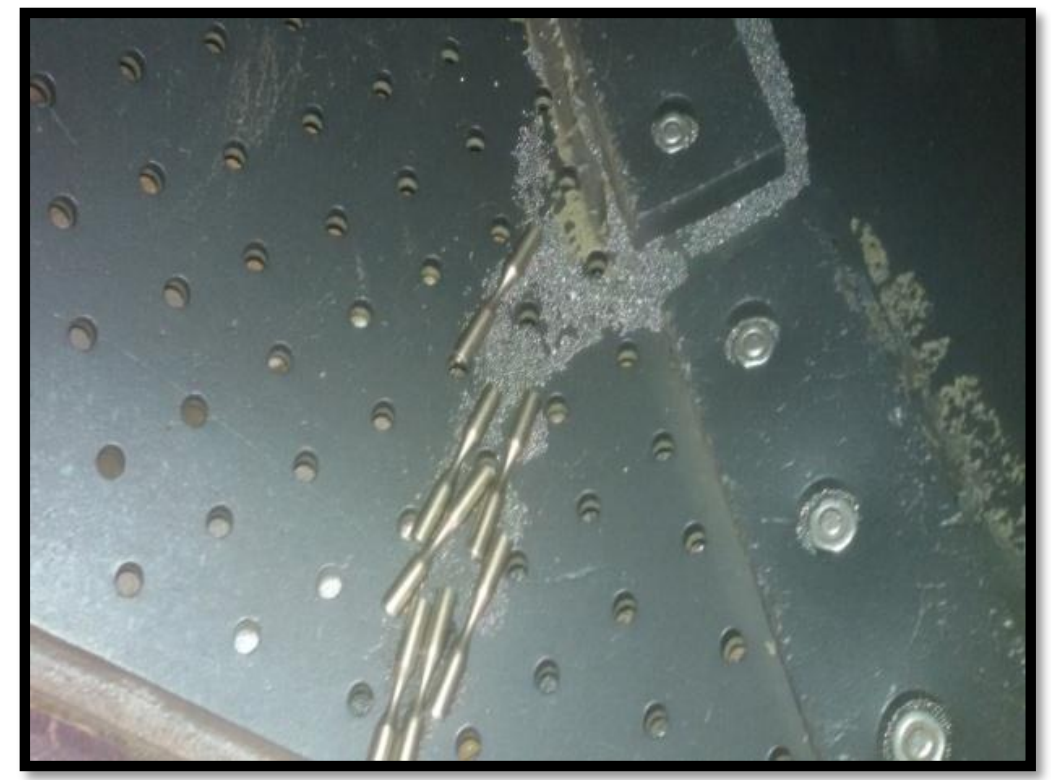

Figure 3 Shot Peening Device from inside with the samples and shot balls

\subsection{Fatigue Test}

Fatigue tests were carried out by using fatigue test machine of type (HSM19 the rotating bending fatigue 
machine). The fatigue test specimens prepared according to (DIN) standard specifications as shown in Figure (4). To get suitable dimensions of fatigue specimens according to standard dimensions of (HSM19 rotating bending fatigue machine), for this, the all specimens were manufactured using conventional lathe machine (Harrison 600, M350, EW700). All specimens were machined with the careful control for producing good surfaces finish and for minimizing residual stress respectively. Specimens are subjected to an applied load from right side of perpendicular to axis of specimens, developing a bending moment. The surfaces of specimens are under the tension and the compression stresses when it rotates. Value of the load $(\mathrm{P})$ is measured by Newton $(\mathrm{N})$, applied to specimens for a known value of stress $(\sigma)$ measured by $(\mathrm{N} / \mathrm{mm} 2)$ and extracted from applying relation below:
$\sigma\left(\mathrm{N} / \mathrm{mm}^{2}\right)=(32 \times 125 \mathrm{P}(\mathrm{N})) /\left(\pi \times \mathrm{d}^{3}\right)$

$\mathrm{P}=$ force in $\mathrm{N}$,

Force arm is equal to $125 \mathrm{~mm}$ and, $\mathrm{d}=$ minimum diameter of the specimen in $(\mathrm{mm})$.

Constant fatigue tests were conducted in laboratory air (approximately $25-30 \%$ relative humidity) at the room temperature on HSM19 rotary fatigue bending machine as shown in figure (5), with a stress ratio of $\mathrm{R}=-1$. Cycle frequency was $50 \mathrm{~Hz}$ and rotating speed used is $(3000$ cycle/min.). This test was carried out in Mechanical Engineering Department/ Al- Mustansiriayah University/ Baghdad/ Iraq

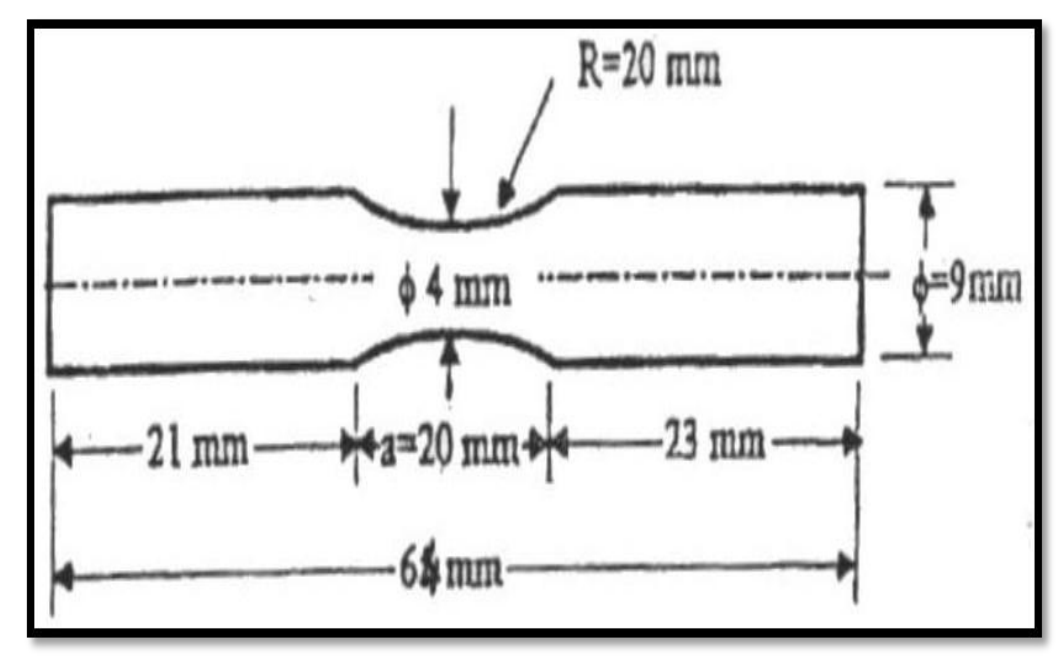

Figure 4 Fatigue test specimen with dimensions in (mm)

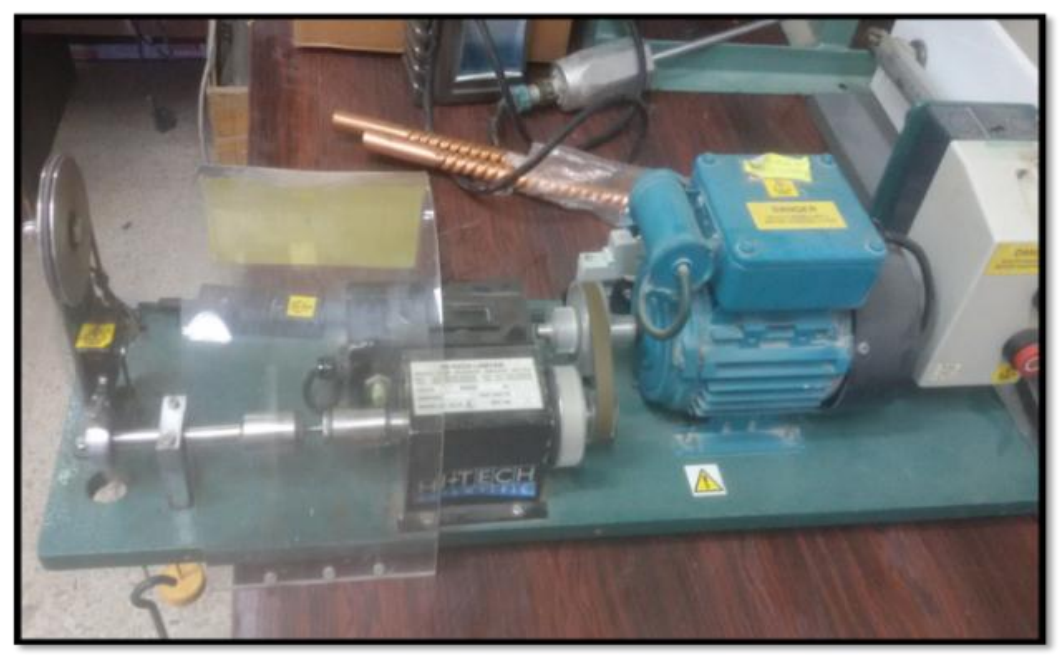

Figure 5 Fatigue testing machine HSM19 (rotating) 


\subsection{Surface Roughness Measurement}

The surface roughness was measured for samples used in this research whose used for fatigue test, and it has found that value of the surface roughness is ranging from $\left(0.156 \_2.181\right)$ Micron. Ten samples subjected to surface roughness measurement, where they were measured by using the surface roughness measuring device (TR200), as illustrated in figure (6)

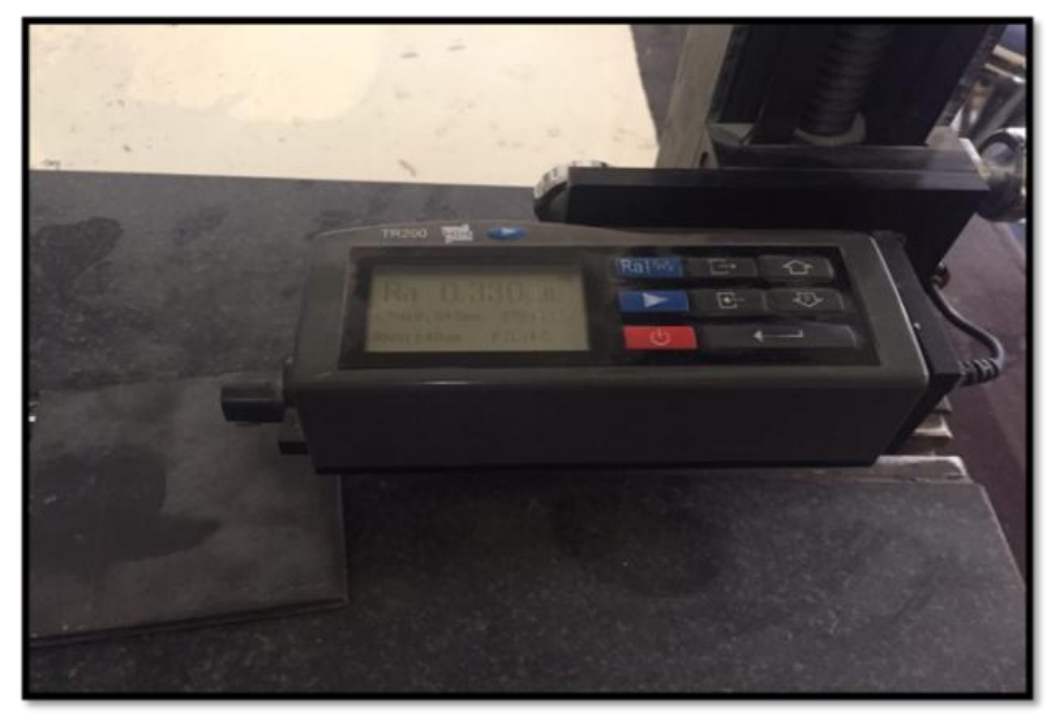

Figure (6) Surface roughness measuring device (TR200)

\subsection{Hardness Test}

Vickers hardness test was done on ten samples with a load of $3 \mathrm{~N}$ with the load holding time of 10 seconds. The indentations were made starting $0.25 \mathrm{~mm}$ from edge end at an interval of $0.25 \mathrm{~mm}$ to a distance of $3 \mathrm{~mm}$ towards middle and were repeated when specimens were turned at the right angles from first measurement. Device used is shown in figure (7). The device name is (INNOVA Test).This test was carried out in Material Engineering Department/ Al- Mustansiriayah University/ Baghdad/ Iraq.

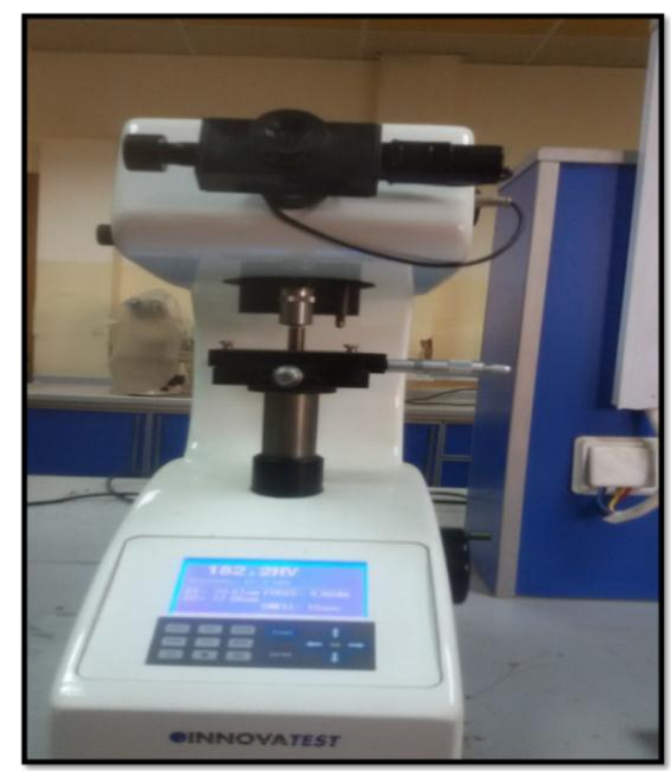

Figure 7 Micro hardness (INNOVA Test) 


\section{Results and Discussion}

\subsection{Fatigue Test}

Fatigue resistance tests were carried out on groups of samples treated superficially by shot peening process, while group of them untreated with any process. In shot peening process, different time values were used for enhancing fatigue resistance. The figures below show these experiments, where ten samples were taken for the each experiment.

\subsection{Discussion the Results of Fatigue Test}

Figures [(8), (9), (10) and (11)] explained the fatigue curves for each condition, it can be seen that the highest value of fatigue limit was $(119.36 \mathrm{MPa})$ for samples that treated with (30) minutes time of shot peening process, this is due to creation high residual compressive stress at surface of specimens and also reduce the crack initiation and increase dislocations density during this process.

Table (2) show the experiment conditions, the fatigue limit and No. of cycle. It was found that there is an improvement in fatigue limit for sample treated with shot peening.

Table (2) the results for fatigue of low carbon steel (AISI 1008)

\begin{tabular}{|c|c|c|c|}
\hline Cases & Treatment & $\begin{array}{c}\text { Fatigue limit } \\
(\mathbf{M P a})\end{array}$ & No. of cycle \\
\hline A & With out treatment & 79.57 & $2 \times 10^{6}$ \\
\hline B & Shot peening for (10 min.) & 99.47 & $5 \times 10^{6}$ \\
\hline C & Shot peening for (20 min.) & 109.41 & $7 \times 10^{6}$ \\
\hline D & Shot peening for (30 min.) & 119.36 & $1 \times 10^{7}$ \\
\hline
\end{tabular}

\subsubsection{Group (A) Fatigue Test of as Received Low} Carbon Steel (AISI 1008)
The fatigue limit of untreated low carbon steel (AISI 1008) was at $79.57 \mathrm{MPa}$

Ten Samples were tested at room temperature. The applied stresses were in a range of (79.57-169.102 MPa).

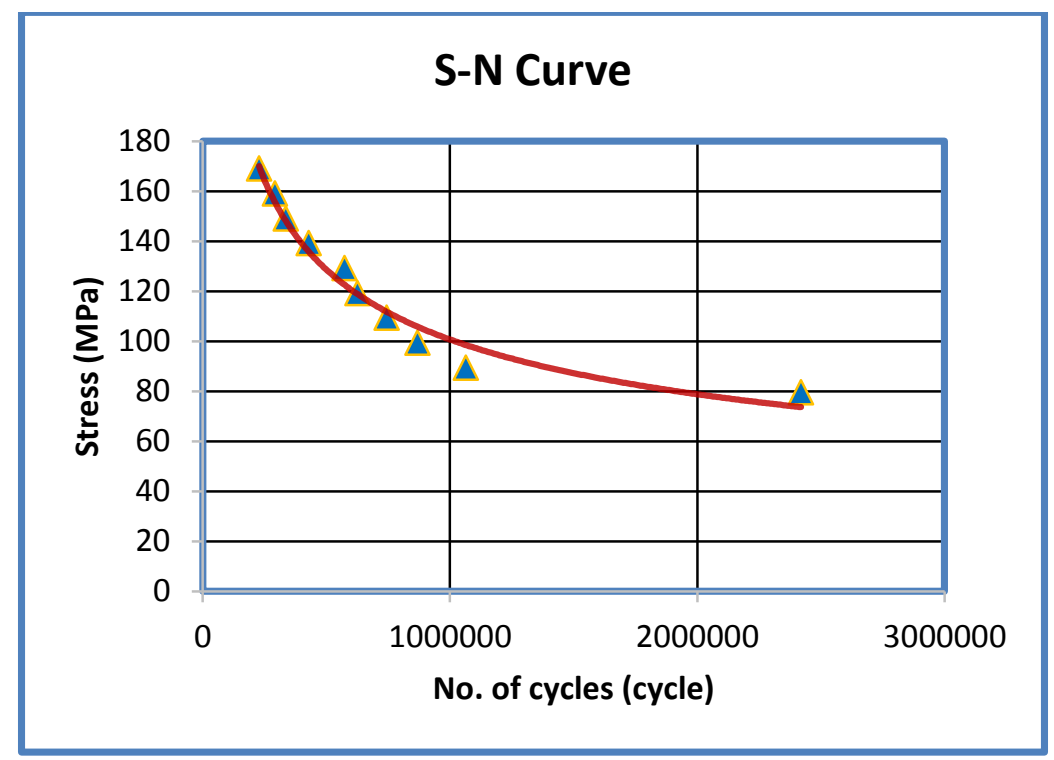

Figure 8 S-N curve for untreated low carbon steel AISI 1008 
This group (untreated low carbon steel AISI 1008) subjected to fatigue test in different stresses to extract value of fatigue limit which was $79.57 \mathrm{MPa}$ as shown in figure (8).

\subsubsection{Group (B) Fatigue Test of (10) Minutes Shot Peened Low Carbon Steel (AISI 1008)}

Ten Samples were tested at the room temperature. The applied stresses were in a range of (99.47-198.94 MPa). The fatigue limit of (10) minutes shot peened low carbon steel (AISI 1008) was at $99.47 \mathrm{MPa}$.

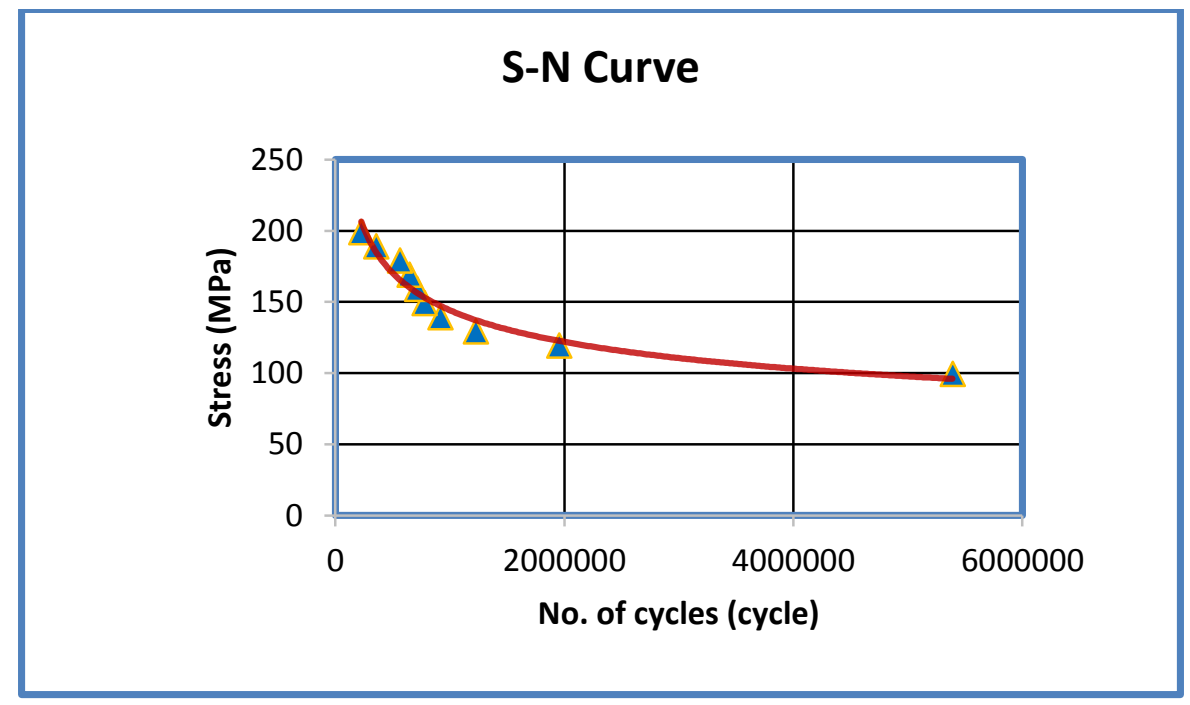

Figure 9 S-N curve for low carbon steel (AISI 1008) that treated with shot peening for 10 minutes

This group treated with 10 minutes time of shot peening process and then subjected to fatigue test at room temperature and the result was that fatigue limit of this group is $99.47 \mathrm{MPa}$ as shown in figure (9), this value higher than untreated one, this is due to produce residual compressive stresses at surface of specimens during shot peening process.

\subsubsection{Group (C) Fatigue Test of (20) Minutes Shot Peened Low Carbon Steel (AISI 1008)}

Ten Samples were tested at room temperature. The applied stresses were in a range of (109.41-198.94 MPa). The fatigue limit of (20) minutes shot peened low carbon steel (AISI 1008) was at $109.41 \mathrm{MPa}$.

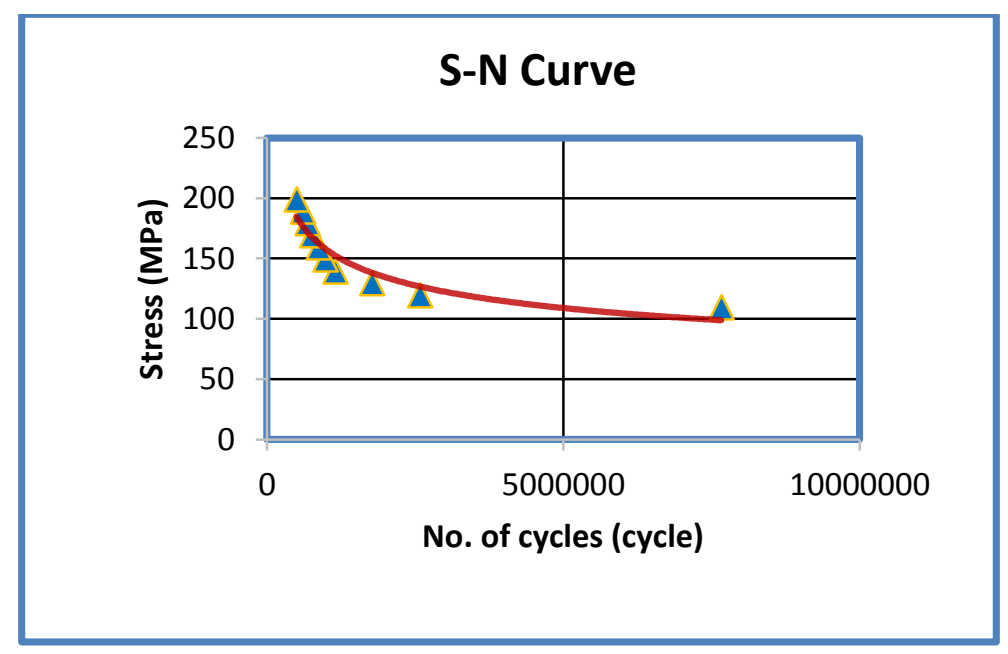

Figure 10 S-N Curve for low carbon steel (AISI 1008) that treated with shot peening for 20 minutes 
This group treated with 20 minutes time of shot peening process and then subjected to fatigue test at room temperature and the result was that fatigue limit of this group is $109.41 \mathrm{MPa}$ as shown in figure (10), this value higher than untreated one, this is due to produce residual compressive stresses at the surface of specimens which lead to prevent crack initiation.

\subsubsection{Group (D) Fatigue Test of (30) Minutes Shot Peened Low Carbon Steel (AISI 1008)}

Ten Samples were tested at room temperature. Applied stresses were in a range of (99.47-2118.83 MPa). The fatigue limit of (30) minutes shot peened low carbon steel (AISI 1008) was at $119.36 \mathrm{MPa}$, this is highest fatigue limit obtained during achievement shot peening process.

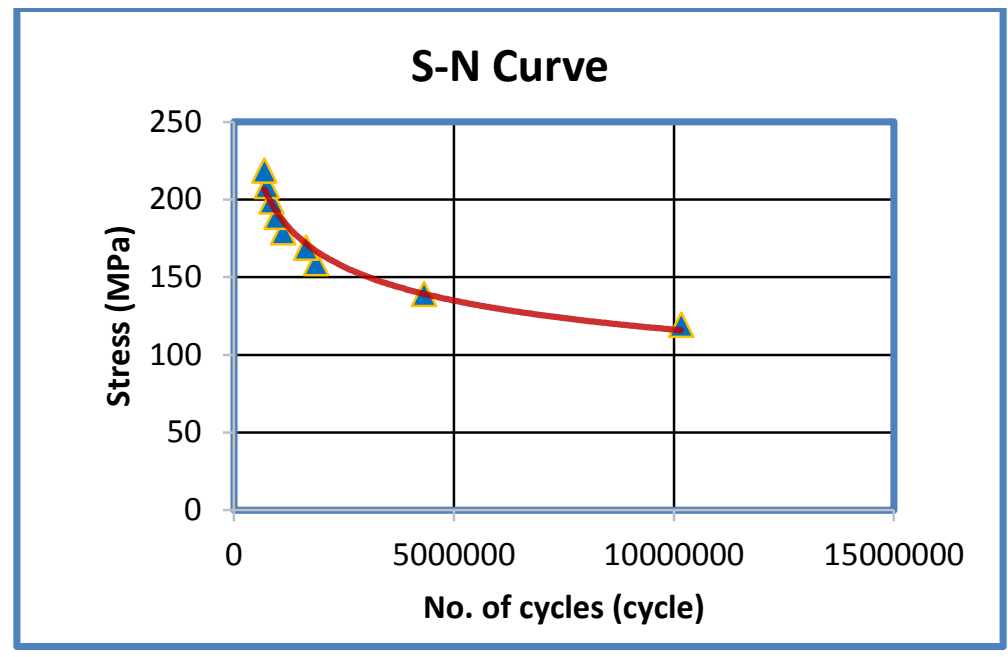

Figure 11 S-N curve for low carbon steel (AISI 1008) that treated with shot peening for 30 minutes

This group treated with 30 minutes time of shot peening process and then subjected to fatigue test and the result was that fatigue limit of this group is 119.36 $\mathrm{MPa}$ as shown in figure (11), the fatigue limit improved because this process lead to impart compressive residual stresses of surface layer of the specimens that is one of ways for improving their fatigue strength characteristics.

\subsection{HARDNESS MEASUREMENT}

The hardness of the samples have been measured by using the Vickers hardness method, and it can be seen that the hardness value increased for the samples generally for the surface treated samples with shot peening. Hardness values for samples treated with shot peening process are higher than those which non-treated as illustrated in table (3) below

Table (3) Values of the hardness for Vickers for samples of low carbon steel (AISI 1008)

\begin{tabular}{|c|c|c|}
\hline Cases & Treatment & $\begin{array}{c}\text { Hardness rate } \\
\text { for Vickers (HVN) }\end{array}$ \\
\hline A & With out treatment & 169.53 \\
\hline B & Shot peening for $(10$ min. $)$ & 192.66 \\
\hline C & Shot peening for $(20$ min. $)$ & 221.56 \\
\hline D & Shot peening for $(30$ min.) & 235.1 \\
\hline
\end{tabular}


Where the surface of sample is treated with shot peening process undergo compressive stresses, as well as with increased dislocations density, which led to increase the alloy surface hardness. The untreated alloy with shot peening process has few dislocations density. The treatment of the alloy surface by shot peening process has led for increasing the hardness of the alloy surface compared to untreated one due to increasing the dislocation lines and hardening for the metal surface.

\subsection{Discussionof Hardness Results}

In Figure (12) it can be seen the change in the hardness values. When the time of shot peening increased for the samples, this is due to increase the dislocations density, the hardness values increased of the surface of alloy. From table (3) it can be seen the highest hardness value in 30 minutes shot peened sample which is (235.1 HVN), from this we can conclude that highest value of dislocations density occurred in this sample

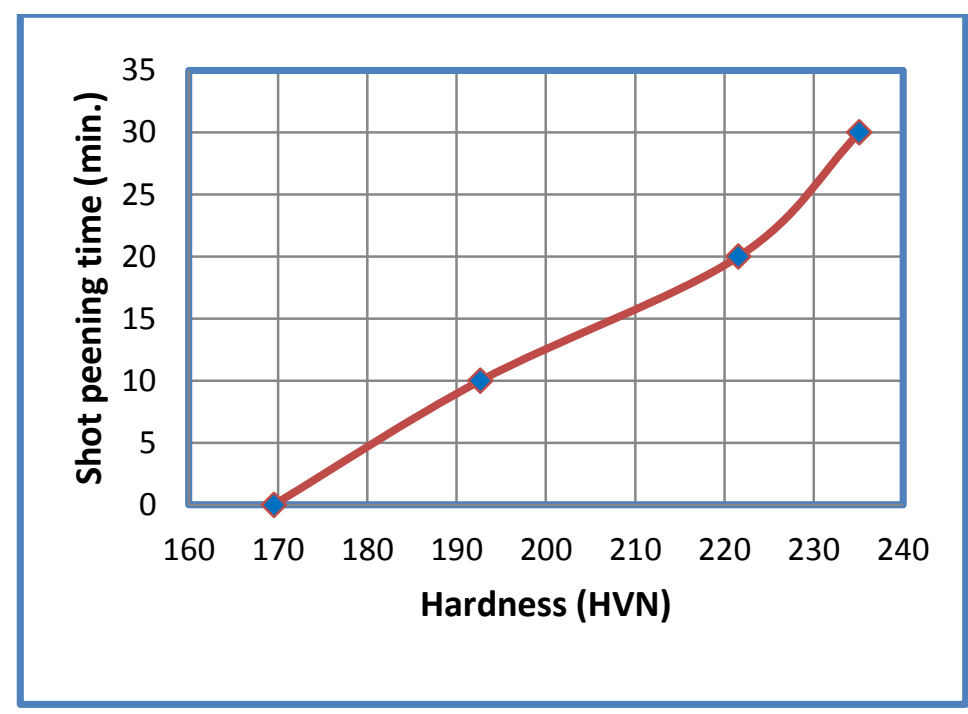

Figure 12 Influence the time of shot peening process (10, 20, $30 \mathrm{~min}$.) on the hardness values of the samples for steel AISI 1008

Figure (12) explained that the times of shot peening used in this research are $(10,20,30)$ minutes. The result showed that increasing the time of shot peening lead to increase the value of surface hardness for the specimens this is due to increase the dislocations density, which led to increase hardness values of alloy surface. Highest value of hardness obtained when time of shot peening was (30) minutes which was (235.1) HVN.

\subsection{Surface Roughness Measurement}

The surface roughness of samples have been measured, and it has been found that surface roughness values increased for samples that treated with shot peening. The values of surface roughness for the samples treated with the shot peening process are higher than those which non-treated as illustrated in table (3).

\subsection{Discussion the Results of Surface Roughness}

From table (4) it can be found that surface roughness values for all samples at different conditions. From figure (13) it can be remarked that the surface roughness increases for samples that treated with shot peening. The highest value of surface roughness was $(2.181 \mu \mathrm{m})$ for samples treated with (30 minutes) time of shot peening process and this due to the increase of surface temperature as the shots incident with the surface causing peaks and valleys on the surface, in this case the surface of sample loss it fineness. 
Table (4) the values of surface roughness values for samples of low carbon steel (AISI 1008)

\begin{tabular}{|c|c|c|}
\hline Cases & Treatment & Surface roughness $(\mu \mathrm{m})$ \\
\hline A & With out treatment & 0.237 \\
\hline B & Shot peening for (10 min.) & 1.537 \\
\hline C & Shot peening for (20 min.) & 1.756 \\
\hline D & Shot peening for (30 min.) & 2.181 \\
\hline
\end{tabular}

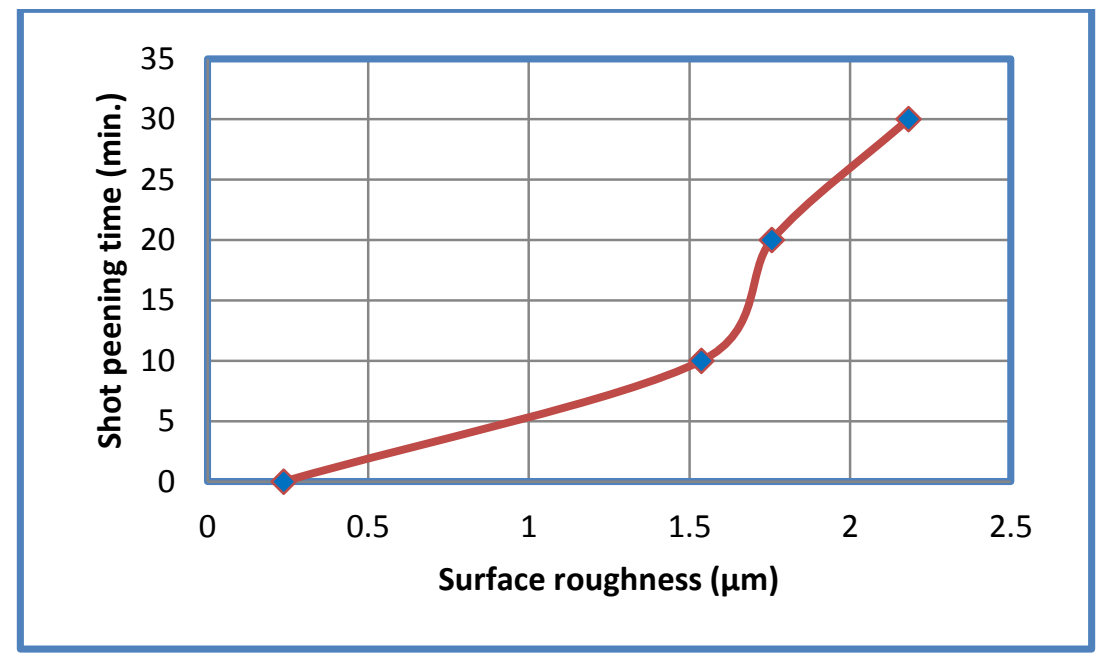

Figure 13 Influence the time of shot peening $(10,20,30$ minutes) on the surface roughness on the samples

Figure (13) shows that times of shot peening used in 2. Increasing time of shot peening led to increase hardness are $(10,20,30)$ minutes. The result showed that increasing the time of shot peening lead to increase the surface roughness for the specimens this is due to produce peaks and valleys on the surface of selected metal, in this case the surface of specimens loss it fineness. The highest value of surface roughness obtained when time of shot 3 . peening was (30) minutes which was $(2.181) \mu \mathrm{m}$.

\section{CONCLUSIONS}

Improvement the mechanical properties for low carbon steel AISA 1008 by using shot peening process yielded the following conclusions:

1. Increasing time of shot peening led to improve fatigue limit, where highest value of fatigue limit obtained from 30 minutes time of shot peening process which was (119.36 Mpa). value, where highest value of hardness obtained from 30 minutes time of shot peening process which was (235.1 HVN).

Increasing time of shot peening led to increase surface roughness value, where highest value of surface roughness obtained from 30 minutes time of shot peening process which was $(2.181 \mu \mathrm{m})$.

\section{References:}

[1] Jack Champaigne "Shot Peening Overview", Electronics Inc 1428 W, 6TH Street Mishawaka, In 46544, January 18, 2001.

[2] P.M. George, NishaPillai, Nisha Shah, Optimization of shot peening parameters using 
Taguchi technique, Journal of Materials Processing Technology 153-154, 925-930, 2004.

[3] A. N. Abood et.al "Strain Life of Shot Peening AA 2024-T4" Journal of Materials Science Research, Vol. 2, No.1, 2013.

[4] Metal Improvement company "Shot Peening Applications" A Subsidiary of Curtiss-Wright Corporation, ninth edition.

[5] Wagner, L., Luetjering G., "Influence of shot peening on the fatigue behavior of titanium alloys", Proceedings of the 1stInt, Con, SP.,(Paris, France), 1981.

[6] M.A.S. Torres and H.J.C. Voorwald, "An evaluation of shot peening, residual stress and stress relaxation on the fatigue life of AISI 4340 steel", International Journal of Fatigue 24, 877886, Brazil, October 2001.

[7] S. Van Wijk, M. François and E. Sura, "ShotPeening of Carbonitrided Steel: Influence of the Process on the Mechanical State", France, 2010.

[8] S.M.H. Gangaraj and G.H. Farrahi, "Side Effects of Shot Peening on Fatigue Crack Initiation life", Department of Mechanical Engineering, Sharif
University of Technology Tehran, Iran, 15, September, 2011.

[9] Hornbogen, E., Thumann, M. and Verpoort, C. "Influence of shot peening on the fatigue behavior high cycle fatigue properties of a precipitation hardenableaustenitic steel", pp. 381-387, 1981.

[10]Herzog, R., Wohlfahrt, H., Scholtes, B. and Zinn, W., "The significance of Almen intensity for the generation of shot peening residual stresses", in ICSP-6 (San Francisco, USA), pp. 270-281, 1996.

[11] Wang $\mathrm{S}$ et al. "Fatigue limits of shot-peened metals", J Mater Process Technol 1998;73:5763.

[12] W. Shengping, L. Yongjun, Y. Mei, W. Renzhi, "Fatigue limits of shot-peened metals"Journal of Materials Processing Technology 73, 57-63, 1998.M. Guagliano, L. Vergani, "An approach for prediction of fatigue strength of shot peened components", Engineering Fracture Mechanics 71, 501-512, 2004. 